\author{
TENDENCIAS \\ Revista de la Facultad de Ciencias Económicas \\ y Administrativas. \\ Universidad de Nariño \\ Vol. VII. No.2 \\ Segundo semestre 2006, páginas 139-166
}

\title{
EL DESARROLLO LATINOAMERICANO: PASADO, PRESENTE Y FUTURO. UN HOMENAJE A ANDRÉ GUNDER FRANK ${ }^{12}$
}

\begin{abstract}
Por: Theotônio dos Santos ${ }^{3}$
La temática del desarrollo, bajo diversas formas y presentaciones, ha sido una constante en el pensamiento social latinoamericano. El siglo XIX estuvo, en gran parte, dominado por el debate entre civilización y barbarie. La élite "criolla" veía sus países retrasarse cada vez más dentro de un mundo en muy rápida evolución, en el cual prevalecían los valores culturales de Europa occidental. Este atraso parecía explicarse por la presencia cultural, social y étnica mayoritariamente no europea. Dentro de la supuesta confrontación entre el Occidente avanzado y el Oriente atrasado, los latinoamericanos se sentían más cercanos del Oriente que del Occidente.

Esta percepción derrotista asume también la forma de localizar a América Latina en el polo negativo de la dicotomía entre lo moderno y lo arcaico, entre lo urbano y lo rural, entre el progreso y el atraso. El progreso se convirtió, incluso, en una de las categorías fundamentales del pensamiento de las clases medias latinoamericanas, muy influenciadas por el

\footnotetext{
${ }^{1}$ Tomado de: Dos Santos, Teotonio: "El desarrollo latinoamericano: pasado, presente y futuro. Un homenaje a Andre Gunder Frank”, Problemas del Desarrollo, vol. 27, no. 104, UNAM, México, enero-marzo 1996. Traducción: Ana Esther Ceceña, Investigadora del Instituto de Investigaciones Económicas, UNAM. También disponible en:

http://www.rrojasdatabank.org/agfrank/bio_spanish.doc

${ }^{2}$ Este texto fue preparado para la edición conmemorativa de los 65 años de André Gunder Frank, El subdesarrollo del desarrollo-Ensayos para André Gunder Frank, organizada por Sing C. Chew y Robert Denemark.

${ }^{3}$ Profesor titular de la Universidad Federal Fluminense de Brasil.
} 
Theotônio dos Santos. EI desarrollo latinoamericano: pasado, presente y futuro. Un homenaje a André Gunder Frank

pensamiento positivista. El positivismo-colocaba el desarrollo de la industria, de la ciencia y de la tecnología como meta histórica de la civilización y su implantación como resultado de la acción de una clase industrial.

Este progreso que América Latina no lograba protagonizar será vislumbrado, en la segunda mitad del siglo XIX, como el resultado de la importación de conocimientos científicos y tecnologías, y no como el desarrollo propio y autónomo de los mismos. La ideología del progreso reflejaba el, punto de vista de las clases medias que buscaban equipararse con los sectores medios y clases dominantes de los países centrales, hacia donde América Latina exportaba y desde donde importaba.

Esa visión dicotómica comenzará a ser revisada entre las décadas de los años veinte y treinta de este siglo, cuando se consolida la perspectiva de industrialización de la región. Es así como, consecuentemente, empiezan a reformularse esos pares dicotómicos.

En las dos décadas siguientes se desarrolla el pensamiento de la (Comisión Económica para América Latina (CEPAL), perteneciente a las Naciones Unidas, que va a otorgar un fundamento de análisis económico y un sustento empírico, así como un apoyo institucional, a la búsqueda de bases autónomas de desarrollo. Éstas se definirán a partir de la ubicación de la industrialización como elemento aglutinador y articulador del desarrollo, del progreso, de la modernidad, de la civilización y de la democracia política.

La industrialización se llevó a cabo sobre todo en Brasil, México, Argentina y, en menor grado, en Chile y Colombia. Para las corrientes más modernas en estos países la industrialización era la clave del desarrollo. El atraso, lo arcaico, la barbarie, eran resultado de la especialización de estas economías volcadas hacia la exportación de productos primarios. Algunos autores, como Gilberto Freire, denunciaban la monoproducción como destructora de alternativas económicas. Otros denunciaban al capital extranjero, que tuvo un papel muy importante en la creación del sector exportador de varios países, por sustentarse en verdaderos "enclaves del exterior", que no producían ningún efecto sobre las economías nacionales, Las inversiones en los sectores exportadores no generaron economías externas". 
Se va consolidando así la noción de subdesarrollo como expresión de una situación económica, social, política y cultural en la que se combinan, de forma negativa, el "enclave", el monocultivo, la cuestión racial, el colonialismo interno y el llamado "dualismo" económico. Este conjunto de elementos actúan unos sobre otros y configuran una situación de atraso o subdesarrollo, un círculo vicioso que era necesario romper para conseguir encaminarse hacia el desarrollo.

Mientras tanto, el conjunto de transformaciones asociadas a la industrialización eran asumidas bajo el título de revolución burguesa. Gran parte de la problemática del desarrollo se inscribía dentro de la discusión en torno a la necesidad de una revolución burguesa en América Latina. Era su ausencia la que explicaba el atraso de la región.

La revolución burguesa comprendía también el problema agrario, contemplado bajo dos aspectos: el de la destrucción del latifundio como fuerza política y económica, sustento del dominio de las oligarquías rurales y de los sectores exportadores de productos primarios. Tenía así, por lo tanto, un contenido político, social y económico: la lucha contra el latifundio. Por otro lado, el latifundio se mostraba corno generador de desigualdad económica social y como obstáculo al desarrollo del campesinado y a la constitución del mercado interno.

La reforma agraria aparecía, consecuentemente, como una solución para esos dos grandes problemas y contaba con antecedentes históricos de extrema importancia en la región como la Revolución Mexicana, que tuvo una gran fuerza de irradiación ideológica sobre todo el continente. Esta revolución se desdobló en las luchas revolucionarias de la década de 1910 y en las luchas por la creación del Estado moderno, nacional y democrático, alcanzado a través de la Constitución mexicana de 1917. En ella se afirmaba el principio de la reforma agraria, de la propiedad nacional de la minería y de las riquezas nacionales, del Estado como regulador de la economía y del progreso vinculado a las transformaciones sociales, económicas y políticas.

La irradiación de los ideales de la Revolución Mexicana fue todavía más importante en la década de los treinta cuando el gobierno de Cárdenas los profundiza y radicaliza, llevando la reforma agraria a un terreno más amplio al intentar desarrollar las cooperativas y los ejidos mexicanos, inspirados en 
Theotônio dos Santos. EI desarrollo latinoamericano: pasado, presente y futuro. Un homenaje a André Gunder Frank

la Revolución rusa. A través de la nacionalización del petróleo Cárdenas asentaba el principio del monopolio estatal de las riquezas nacionales y mediante la institucionalización del plan económico defendía la necesidad del Estado de conducir el proceso de industrialización.

A partir de la conformación de las centrales campesinas y obreras como fuerzas fundamentales de conducción del Estado mexicano se configura un cuadro político en el que la democracia liberal es sustituida por una democracia participativa, donde la organización política y sindical de los trabajadores constituía una de las bases fundamentales de un concepto democrático distinto, muy inspirado en los procesos revolucionarios socialistas mundiales, que se consagraban en el proceso mexicano a través de la idea de la educación socialista.

La irradiación de la influencia mexicana se cristaliza en figuras como Haya de la Torre, creador de la APRA peruana que sostenía el concepto de indoamérica. En él y en otros líderes políticos de la región las cuestiones social, racial, étnica y cultural se entremezclaban para dar cuerpo a la autonomía de las naciones latinoamericanas. Esta autonomía se fundaba en la afirmación de las poblaciones indígenas, tesis que va a tener influencia incluso en los partidos comunistas, que se verán obligados a adaptar la ideología de la Tercera Internacional a las condiciones específicas del Tercer Mundo en general y de América Latina en particular.

En un intento por imitar la discusión que se llevaba a cabo en Asia (sobre todo en India y China), se procuraba detectar en América Latina una población autóctono, dominada por los europeos, por la colonización y por el imperialismo. Las poblaciones indígenas aparecían como la fuente de una lucha social que sería también económica y política. En los años veinte, Mariátegui buscó demostrar que la cuestión indígena tenía su fundamento en la cuestión agraria. Mella destacó el papel de los movimientos estudiantiles y Ponce colocó en primer plano la necesidad de la educación.

Pero el marxismo latinoamericano no podía escapar de este contexto más global formado por el pensamiento democrático latinoamericano que se desarrolló durante el siglo XIX, más precisamente hacia el final, en autores como Martí y Hostos, que luchaban por la afirmación nacional, antiimperialista y anticolonial en Cuba y en Puerto Rico. 
Independientemente de los debates sobre cuestiones específicas, el cuadro, en conjunto, se caracterizaba por la necesidad de pasar por una revolución burguesa en América Latina. Esta revolución burguesa necesitaba de una clase protagónica que sería una burguesía industrial nacional.

Las fuerzas sociales y los movimientos de izquierda, particularmente los partidos comunistas, alcanzaron su auge político en América Latina entre los años treinta y cincuenta. En esta época la Unión Soviética como gran potencia industrial y como vencedora de la Segunda Guerra Mundial, atrajo el apoyo de la intelectualidad, de gran parte de la tecnocracia, de sectores de la industria (incluso empresariales) como modelo de solución de los problemas del atraso económico a través de la planificación. Algunos autores invocaban el concepto de Schumpeter del empresario innovador para caracterizarlo como el protagonista de esa revolución. Se trataba de superar un cuadro histórico marcado por las "reminiscencias feudales" precapitalistas, interpretadas de diversas maneras. Sin embargo, en los años treinta y cuarenta la condición de exportador de materias primas, de productos primarios, agrícolas, etc., se va convirtiendo cada vez más e n un obstáculo económico crucial.

La afirmación de ese punto de vista se hace todavía más clara con la creación, en 1947, de la CEPAL, bajo el liderazgo de Raúl Prebisch. Él profundiza en la crítica sobre el papel del sector exportador como el principal obstáculo del "desarrollo económico" y con este enfoque se sustituye, en gran parte, el concepto de revolución burguesa.

La CEPAL era una organización emanada de los gobiernos latinoamericanos, concebida para asesorarlos y proponerles políticas. Sus estudios se concentraron en las políticas capaces de viabilizar el proceso de industrialización procurando la superación de los obstáculos al desarrollo. Sus propuestas, sin embargo, preservaban las estructuras de poder existentes.

El desarrollo industrial de la región se volvió dependiente del sector exportador a través del proceso de sustitución de importaciones. Este proceso fue resultado de una situación histórica y después fue sistematizado en el nivel teórico y conceptual. Fue resultado de algo que André Gunder Frank señaló con mucho énfasis en sus estudios sobre América Latina: las dificultades generadas por las crisis globales del capitalismo mundial. En 
Theotônio dos Santos. EI desarrollo latinoamericano: pasado, presente y futuro. Un homenaje a André Gunder Frank

particular, la crisis de 1929 tuvo un efecto limitante del comercio mundial que se redujo, en la época, cerca del 50\%, disminuyendo las importaciones de la región.

Celso Furtado mostró también como la política de financiamiento de los acervos de café en Brasil mantuvo el ingreso medio del país durante la crisis de 1929 y, por lo tanto, la demanda interna. En otros países se buscó preservar al máximo el poder de compra interno. Se creó así un proteccionismo espontáneo, consecuencia de la crisis económica mundial, que visualizó el desarrollo de la industria nacional permitiéndole sustituir gran parte de los productos que anteriormente se importaban.

Las primera y segunda guerras mundiales cumplieron el papel de limitantes de las importaciones pero, al mismo tiempo, funcionaron como estimuladoras de las exportaciones. En este sentido fueron coyunturas sumamente favorables a la sustitución de importaciones.

Algunos autores, entre los cuales me coloco, llamaron la atención también hacia las crisis ${ }^{4}$ del siglo XIX, que si no produjeron un efecto de industrialización importante fue porque la etapa de desarrollo manufacturero de la región latinoamericana era todavía muy incipiente, impidiendo el aprovechamiento de las circunstancias generadas por la crisis.

Por otro lado, las grandes expansiones económicas mundiales en las décadas de 1850 y 1860 y en el periodo de 1895 a 1914, provocan una fuerte reestructuración de nuestra región a favor de las exportaciones de productos agrícolas y materias primas que demandaba la economía europea (y posteriormente también la estadounidense), en pleno despliegue.

El fenómeno de la sustitución de importaciones surgió como resultado de las crisis y contracciones del comercio mundial y comenzó a ser objeto de sistematización teórica y política en la década de los treinta, cuando en un artículo muy importante en el Boletín del Ministerio de Industria, Comercio y Trabajo, Roberto Simonsen, el gran historiador económico y líder industrial brasileño, lo describió por primera vez.

\footnotetext{
${ }^{4}$ En los años treinta, cuarenta, sesenta, ochenta y noventa.
} 
En la década de los años cincuenta la CEPAL estudió las particularidades de este proceso de sustitución de importaciones: se inicia por la sustitución de importaciones de productos de consumo, sobre todo de élite, que rápidamente se saturan. En los años cuarenta la sustitución de importaciones se orienta hacia los bienes de consumo durable y solamente en una última etapa, ya en la década de los sesenta, comienza una sustitución en el sector productor de maquinaria. Esa característica del proceso de industrialización basado en la sustitución de importaciones provocó que el crecimiento industrial dependiera enormemente de las divisas obtenidas con las exportaciones. En algunos casos éstas fueron radicalmente apropiadas o incluso expropiadas por el Estado para beneficio del proceso de industrialización. Es el caso típico de Brasil, donde la estatización del comercio exterior se asentó definitivamente en la década de los treinta, con la apropiación del Estado de las divisas obtenidas con las exportaciones para pagar a los exportadores en moneda nacional.

Esta política fue objeto de la reacción latifundista y comercial exportadora, que denunciaba la llamada "confiscación cambiaria". La política cambiaría pasó a definir el valor de la moneda nacional frente a las internacionales a través de las tasas de cambio, teniendo un efecto profundo sobre la riqueza del sector exportador. Éste recibía en moneda nacional el resultado de sus exportaciones y era obligado a invertir y a comprar sus productos de consumo en el mercado interno.

Esa articulación estructural entre la sobrevivencia del sector exportador y la industrialización configura una alianza política muy propia de los países latinoamericanos, en los cuales encontramos una política de perduración del latifundio apoyada por la burguesía industrial. Esta burguesía vio así limitada su dimensión revolucionaria, teniendo que abandonar la perspectiva de confrontación con las oligarquías tradicionales y de distribución del ingreso en el campo, que generase un mercado interno más significativo. No fue capaz de vender medios de producción y productos de consumo para la masa campesina y de aumentar así la capacidad productiva a través de la expansión de su demanda interna. Se creó, en consecuencia, un bloqueo estructural al desarrollo económico de la región.

Esta limitación estructural se reflejaba claramente en el pensamiento de la CEPAL. La CEPAL, representante en gran medida de esa burguesía industrial, buscó salidas que no afectaran la cuestión agraria y que 
Theotônio dos Santos. EI desarrollo latinoamericano: pasado, presente y futuro. Un homenaje a André Gunder Frank

permitieran expropiar recursos del latifundio mediante mecanismos de intervención estatal, sin llegar al enfrentamiento con él. Uno de esos mecanismos fue la inflación, que permitía una política de precios relativos favorable al sector industrial. Otro mecanismo, como vimos, fue la nacionalización de las divisas y de la política cambiaría; finalmente, fueron empleados recursos basados en la intervención directa del Estado en la economía rural como subsidios a la producción exportadora, protección a los productos agrícolas de consumo popular, etcétera.

La naturaleza capitulacionista de la burguesía en la región se manifestaba también en su actitud conciliadora frente al capital externo. A pesar de reconocer su carácter expoliador, requería de él en virtud del control que ejercía sobre la tecnología y sobre los mercados internacionales, dominados por poderosos cárteles y monopolios. El capital internacional dominaba gran parte de los sectores orientados a la exportación, la energía, los transportes, las comunicaciones y en algunos casos la industrialización de los productos exportados o el control de su comercialización.

En este contexto, el capital internacional aparecía como un aliado de la estructura latifundista o minero exportadora, de la economía de monocultivos, del latifundio que mantenía relaciones de trabajo semiserviles que se caracterizaban, en general, como "precapitalistas". André Gunder Frank tuvo un papel sumamente positivo al caracterizar, en la década de los sesenta, a estas economías como una modalidad del capitalismo surgida de la evolución de la economía mundial y de la división internacional del trabajo. Es verdad que esta modalidad capitalista dependiente y subordinada se encontraba bajo la hegemonía del capital mercantil y no desarrollaba elementos esenciales para el avance del capitalismo, tales como un régimen asalariado y la formación de un proletariado moderno. Pero no nos olvidemos que el primer proletariado latinoamericano surgió vinculado al sector exportador. Las primeras manifestaciones proletarias en la región están notoriamente asociadas a los centros mineros donde se constituyó un proletariado minero con cierto grado de organización, cuyos ejemplos más brillantes se encuentran en Chile y Bolivia. Fue también en el sector ferroviario, orientado hacia la expedición de las exportaciones, donde surgió otra categoría fundamental del movimiento sindical latinoamericano. Fueron también los asalariados agrícolas de la United Fruit los que marcaron, en América Central y el Caribe, su presencia revolucionaria en los años veinte y treinta. 
Solamente a finales del siglo XIX y en los años de la primera guerra mundial se constituyó un puñado de obreros industriales. Su carácter artesanal se expresaba en su orientación ideológica anarquista predominante en la región hasta el fin de los años veinte. Apenas en los años treinta se empieza a desarrollar una industria nacional con la formación de los tejedores, de los metalúrgicos y de un sindicalismo industrial urbano.

La burguesía industrial latinoamericana, que nacía en el proceso de industrialización de los años treinta y cuarenta, se encontraba en una situación difícil frente al capital internacional. Aspiraba a sustituirlo pero sin tener el conocimiento tecnológico ni el peso financiero para llevar a cabo las grandes inversiones que eran necesarias para asegurar su competitividad en una fase más avanzada del desarrollo tecnológico. Así, tuvo que apoyarse en el Estado para cumplir gran parte de esa tarea, sobre todo en aquellos sectores donde el capital internacional se rehusaba a

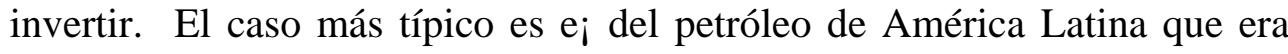
considerado por los centros estratégicos mundiales más como una reserva de Estados Unidos que como un campo de explotación. Esto lleva al capital internacional a mostrar desinterés por las inversiones petroleras, excepto en el caso de Venezuela donde era abundante, barato y se encontraba a ras del suelo. Era entonces natural que en general el capital internacional apareciera como una restricción a la industrialización de la zona y como un apoyo al sector exportador y a la oligarquía rural, minera y comercial exportadora.

Se trataba, entonces, de orientar la inversión internacional, y ésta es la problemática que la CEPAI, intenta enfrentar práctica y conceptualmente al ubicar al capital internacional como un elemento esencial de apoyo al desarrollo económico e industrial de nuestros países. El capital internacional aparecía como complemento del ahorro interno, necesario para la industrialización. En la práctica, el capital internacional podía traer del exterior maquinaria, un sistema de producción, una tecnología que el capital nacional no poseía, Pero raramente se disponía a traer los recursos para su funcionamiento en la economía local. Por el contrario, buscaba apoyo en el ahorro interno de los países donde invertía para financiar su instalación. Necesitaba, por ejemplo, de una amplia infraestructura energética, de vías férreas, de comunicaciones, etc., que correspondía garantizar a los países receptores. Así, se realizaron varias misiones estadounidenses en los años 
Theotônio dos Santos. EI desarrollo latinoamericano: pasado, presente y futuro. Un homenaje a André Gunder Frank

de la posguerra, con el fin de promover la creación de esta infraestructura de energía y transportes capaz de soportar la entrada masiva de inversiones industriales en las décadas de los cincuenta y sesenta.

El pensamiento económico de la CEPAI, seguía un camino paralelo a esas tendencias históricas. En la década del cincuenta se concentró en la crítica a la exportación de productos primarios, señalando su límite histórico a través del mecanismo del deterioro de los términos del intercambio. Mostró también que la hegemonía del sector exportador, tal como estaba configurado, era un obstáculo al proceso de industrialización. Pero, al mismo tiempo, indicaba que era necesario extraer excedente de este sector para dedicarlo al sector industrial. Esto exigía mecanismos de intervención indirectos, como la inflación, que permitieran una política de precios relativos más favorable al sector industrial urbano, o la intervención directa del Estado (generando recursos a veces deficitarios) para hacer viable ese proceso de industrialización.

Estamos, por lo tanto, en un contexto bastante novedoso. La temática del desarrollo tal como se presenta en las décadas de los cincuenta y sesenta, bajo la influencia del pensamiento cepalino, ya escapa al debate entre civilización y barbarie, entre lo moderno y lo arcaico, entre el progreso y el atraso, para producir un debate centrado en los términos de desarrollo y subdesarrollo, entre una estructura social moderna, con todas sus ¡aplicaciones sociales y políticas, opuesta a una estructura agraria o minera que debería ser sustituida progresivamente.

En el terreno de la izquierda, particularmente en los partidos comunistas, la misma cuestión se planteaba mediante el concepto de la necesidad de una "revolución democrático-burguesa". Se señalaba la necesidad de una burguesía nacional, que debería ser apoyada por el movimiento proletario obrero urbano y campesino, para realizar las transformaciones democrático burguesas que hicieran posible el progreso de esas regiones. El movimiento obrero se consolidaría dentro de esa nueva sociedad democrática nacional. Esa visión de la revolución democrática se desdoblaba en enfoques de mayor o menor radicalidad: desde aquellos que afirmaban que la revolución democrático burguesa debería ser dirigida por la burguesía nacional hasta aquellos que sostenían que el movimiento obrero y campesino debería asumir el liderazgo de esa revolución burguesa, ya empujando a la burguesía, ya asumiendo directamente las tareas de la revolución 
democrático burguesa. Esa problemática alcanzó su auge en las décadas de los cincuenta y sesenta, cuando se sumó a ella la cuestión del capital internacional y del papel del imperialismo.

El razonamiento era complejo. Esa revolución era nacional y democrática. Para consolidarse tenía que vulnerar el papel del imperialismo como fuerza de sustentación de los sectores exportadores oligárquicos y antiindustrializantes. Pero ¿qué posición tomar en relación con el imperialismo vinculado al sector industrial, esto es, al capital internacional que dirigía sus inversiones al sector industrial? En este caso las posiciones eran todavía dudosas y confusas. La tendencia era la de aceptar a ese capital internacional pero sometiéndolo a cierto control para limitar la repatriación de las utilidades obtenidas y para obligarlo a jugar un papel subsidiario del desarrollo industrial de la región.

Es en este contexto que se inició una reinterpretación de la revolución burguesa en la región y del papel de las economías llamadas "precapitalistas". Fue necesario repensar el papel del desarrollo capitalista en la región y ubicar su evolución económica dentro de la expansión del capitalismo mercantil europeo, particularmente portugués y español. Posteriormente, el capital mercantil es sustituido por el manufacturero y más tarde industrial holandés, francés, inglés y estadounidense. Fue necesaria todavía una revisión profunda del enfoque de nuestra historia, procurando mostrar que las relaciones esclavistas y serviles fueron establecidas por el capital comercial, que se combinó posteriormente con los intereses del capital industrial moderno, necesitado de materias primas y productos agrícolas a precios bajos. Se generó entonces un tipo de servilismo y de esclavismo modernos, muy diferente del esclavismo clásico del régimen servil feudal. Se requería una discusión profunda sobre el pasado pretendidamente feudal de la región.

En ese momento, estudios que habían sido producidos en las décadas de los treinta a los cincuenta, como la historia económica de Roberto Simonsen, o los trabajos de Sergio Bagú sobre el régimen colonial, los de Luis Vitale sobre el capitalismo en Chile, los de Caio Prado Junior sobre la colonización y la cuestión agraria en Brasil y de Celso Furtado sobre el papel del sector exportador, formaban un conjunto de críticas contundentes a la tesis del carácter feudal de la economía colonial. André Gunder Frank se apoya en estas investigaciones para incitar un cambio de paradigma al 
Theotônio dos Santos. EI desarrollo latinoamericano: pasado, presente y futuro. Un homenaje a André Gunder Frank

afirmar que no se podía hablar de una economía feudal en la región pero sí de modalidades de expansión del capitalismo comercial, y después del capitalismo industrial.

Frank ofreció un modelo de interpretación de estas relaciones internacionales que buscaba articular los diferentes niveles de colonización interna y de extracción de excedentes por el exterior desde las regiones más distantes, pasando por las centralizaciones locales, regionales y nacionales, para terminar en las manos del capital internacional. Denunciaba la existencia de un proceso brutal de extracción de excedentes de la región, que imposibilitaba su desarrollo económico. Al contrario de lo que entonces se consideraba, el capital internacional producía un proceso de expropiación de sus riquezas en vez de proveer capitales y colaborar con el desarrollo económico de la región.

Esta constatación va a ser formulada, repensada y rearticulada muchas veces por el pensamiento latinoamericano, que intentó escapar al radicalismo rápido de la visión inicial de Frank. Se buscó balancear la relación entre el ingreso de capitales externos, bajo la forma de maquinaria, tecnología, etc., con la expropiación de las riquezas de la región, bajo la forma de repatriación de utilidades y de precios relativos desfavorables para los sectores agrario y minero. Esa revisión de conjunto tenía enormes ¡aplicaciones en lo que concierne al papel de la burguesía nacional. Algunos autores, como Frank, buscaban sostener la inexistencia de esa burguesía; otros, como Fernando Henrique Cardoso y yo, destacábamos su compromiso creciente con el capital internacional.

Yo personalmente, tanto como el grupo de investigación con el cual trabajé (ver sobre todo el estudio de Vania Bambirra) ${ }^{5}$ optamos por la segunda visión, tratando de demostrar que entre los años veinte y cincuenta hubo un intento de afirmación de una burguesía nacional industrial en la región. Esta burguesía estuvo en la raíz del cardenismo, dio origen al pensamiento de la CEPAL y a modelos ideológicos bastante sofisticados como el ISEB en Brasil; también influenció visiones más pequeño burguesas como la del APRA peruano que se presentó bajo diversas modalidades en el resto de la región. Esta burguesía sirvió de inspiración y apoyo a los movimientos de

5 Bambirra, Vania. El capitalismto dependiente de América Latina, México, Siglo XXI editores, varias ediciones. 
tipo populista, de raigambre nacional democrática, desde sus expresiones más radicales como la Revolución mexicana en sus diferentes versiones, particularmente en la del cardenismo, hasta los de figuras menos radicales, más conservadoras como Perón o Vargas. Todas ellas formaban parte, a pesar de las diferencias, de una visión nacional democrática. Ambos conceptos eran vistos como instrumentos y como condición sine qua non de afirmación de los pueblos; como condición de su desarrollo económico.

Ese enfoque histórico crítico fue desarrollado por la teoría de la dependencia en trabajos míos y del grupo del CESO de la Universidad de Cliile y tuvo uno de sus momentos más brillantes en la obra de Ruy Mauro Marini en 1967, al mostrar en su visión del subimperialismo que la implantación de economías industriales en varios países latinoamericanos daba origen al surgimiento del capital financiero en la región. Este capital financiero no se contentaría sin embargo con la modalidad de desarrollo local sino que aspiraría a un desarrollo regional, a la extracción de excedentes fuera de sus fronteras, y buscaría una conciliación con el capital internacional, algún tipo de alianza que le permitiera consolidarse como capital financiero. Éste era claramente el caso que se configuraba en Brasil, que en ese momento ocupaba la delantera del mismo.

Al mismo tiempo yo intentaba demostrar que los ciclos económicos latinoamericanos —que se encontraban hasta la década del cincuenta profundamente enlazados con los de la economía mundial-, y sus efectos sobre las producciones agrícola y minera, cambiaban de carácter a partir de esa década. En virtud del avance de la industrialización los ciclos empezaban a presentar modalidades endógenas, ciclos de 4 y 10 años que reflejaban ya la interiorización de una industria pesada, con su dinámica tecnológica propia y su consecuente forma cíclica.

Intenté demostrar también que el avance de ese sector industrial imponía la necesidad de establecer una nueva política frente al capital internacional. Este venía a sustituir al capital nacional en el proceso de industrialización, trayendo tecnologías, financiamiento y patrones de competitividad propios de economías que ya contaban con productos tecnológicamente maduros. Era inevitable por tanto que este capital internacional sometiera al capital nacional a su dinámica, que manifestaba la fuerza emergente de una economía mundial basada en un nuevo tipo de empresa multinacional. 
Theotônio dos Santos. EI desarrollo latinoamericano: pasado, presente y futuro. Un homenaje a André Gunder Frank

Debo recordar que yo fui el primero en analizar su expansión en América Latina, particularmente en mi libro El nuevo carácter de la dependencia.

Este conjunto de estudios novedosos llevaba a una reformulación de orden teórico global y exigía una metodología de análisis que ubicara la historia de América Latina en el contexto de la expansión del sistema capitalista mundial y que visualizara, por lo tanto, el surgimiento de esas economías como una modalidad específica de expansión del capitalismo en escala mundial. Esta modalidad se redefinía en cada país, en cada región, en cada localidad, de acuerdo con las estructuras económicas y sociales encontradas por los colonizadores que venían a implantar las economías exportadoras. Los intentos por resolver las limitaciones de las economías locales condujo incluso al comercio esclavo africano, dando lugar a ese violento proceso de trasplante de gran parte de la población africana hacia América Latina, el Caribe y el sur de Estados Unidos, para conformar una economía exportadora del Caribe al Atlántico Sur.

Surgió así un gran complejo económico, dominado inicialmente por el capital comercial y manufacturero, que dio inicio a la implantación de un moderno sistema manufacturero agrícola exportador. Los ingenios de azúcar no podían ser considerados simplemente una economía agraria tradicional o feudal, se trataba más bien de una economía moderna, orientada hacia la exportación y la producción mercantil en gran escala que va a evolucionar hacia una nueva fase con la expansión del capital industrial en Europa y la reconversión de esa región para atender las nuevas demandas del proceso de industrialización europeo.

Todo eso formaba un nuevo contexto de orden global que va a definir las perspectivas de la región latinoamericana. Aquellos países que procuraban salir de este contexto y desarrollar una economía interna, con distribución del ingreso y formación de un mercado interno a través de soluciones políticas propias y creativas, fueron simplemente destruidos. Estos fueron los casos de las misiones indígenas jesuitas -destruidas por la Corona hispano portuguesa- o de las rebeliones de ciertos polos manufactureros en toda América Latina durante los años 1840-1852, o también de la economía manufacturera de Paraguay, que fue arrasada mediante una guerra genocida conocida en Brasil como Guerra del Paraguay. Estos regímenes manufactureros eran aún tempranos y no tenían poder para sobrevivir ante 
la fuerza expansivo de la economía mundial que entraba en un ciclo de crecimiento sumamente exitoso de 1850 hasta 1871 1875.

Los mercados internos locales pudieron generar economías locales más fuertes sólo durante la crisis mundial entre 18711875 y 1895 y, posteriormente, durante la crisis global iniciada con la guerra de 1914 y que se reproduce después en la crisis de 1929 y en la segunda guerra mundial. En estos periodos se establecieron, como vimos, condiciones favorables para el inicio de un proceso de industrialización en la región, bajo la modalidad de la sustitución de importaciones. No obstante esta economía industrial naciente se enfrenta, después de la segunda guerra mundial, al fenómeno de la reestructuración de la economía mundial bajo la hegemonía estadounidense.

Esta reestructuración se basó en la implantación de la revolución científicotécnica y en la expansión y difusión mundial de las tecnologías de producción masiva, particularmente en el sector de bienes durables. Esta expansión generó una nueva fase de inversiones que partía de los centros creadores de esa tecnología hacia el exterior. Por un lado se trataba de modernizar y aumentar la competitividad de estos centros, sustituyendo un parque industrial envejecido durante la depresión económica, de 1918 a 1940-1945. Por el otro lado se trataba de aprovechar la creación de las nuevas industrias de bienes durables que servían de soporte a estas nuevas inversiones internacionales.

Durante las décadas de los cincuenta y sesenta el proceso de industrialización de los países dependientes aún continuaba sustituyendo importaciones, sin embargo, en muchos casos se empezaron a fabricar productos completamente nuevos, innovaciones que fueron introducidas por el capital internacional. El fortalecimiento de las barreras arancelarias establecidas durante los años 30 y 40 había creado condiciones favorables para industrias embrionarias en los países en desarrollo. El capital internacional procuró entonces saltar las barreras arancelarias para invertir en el interior de estos mercados protegidos y beneficiarse de sus ventajas. De esta forma el capital internacional abandonaba su base tradicional de inversiones en los sectores primario-exportadores para invertir en la producción de manufacturas dirigida hacia el mercado interno de los países dependientes y subdesarrollados. 
Theotônio dos Santos. EI desarrollo latinoamericano: pasado, presente y futuro. Un homenaje a André Gunder Frank

La aparición del capital internacional en el campo industrial creaba una nueva realidad para el pensamiento ideológico de la región y generaba un realineamiento de fuerzas que se fue conformando en un amplio proceso de luchas en la década de los cincuenta. Estas luchas fueron marcadas por las revoluciones boliviana (1952), ecuatoriana (1954), venezolana (1958) y cubana (1958-1959), todas dirigidas contra las viejas oligarquías primario exportadoras y los regímenes autoritarios que las sustentaban. Cada uno de estos procesos revolucionarios se enfrenta a una oposición sangrienta del capital internacional y particularmente del gobierno estadounidense. En este periodo se acentúa también la lucha de las fuerzas aliadas al capital internacional contra los líderes v movimientos populistas que mantenían el proyecto nacional democrático. Entre éstas destacó la destitución de Perón (1955) y el intento de impeachment de Vargas que lo llevó a su suicidio (1954).

A finales de esta década se consolidó en Estados Unidos la visión de que la implantación de un proceso de desarrollo requería de una élite militar, empresarial e incluso sindical, que estableciera un régimen político fuerte, glorioso y modernizador. Esta idea se fundamentó en el libro de Johnson Johnson sobre las clases medias latinoamericanas y formó parte de un proyecto político de intervención en la región que tuvo una de sus principales bases en la Universidad de Stanford, en California.

El golpe de Estado de 1964 en Brasil fue el momento fundador de este nuevo modelo. Logró detener a la burguesía nacional más importante del hemisferio occidental, con aspiraciones de convertirse en un poder internacional o por lo menos regional significativo, sustentada en la extensión de su país y en sus riquezas naturales. En sustitución de este proyecto nacional, el régimen militar creado en 1964 daba origen a una modernización fundada en la alianza e integración de esa burguesía con el capital multinacional, consolidando un tipo de desarrollo industrial dependiente, subordinado a las modalidades de expansión v de organización del capitalismo internacional, que sometía a los centros de acumulación local a la lógica de la expansión del centro hegemónico mundial. A partir de entonces, mediante golpes militares sucesivos, fueron sometidas las burguesías locales a condición de socios menores del capital internacional, llevándolas a abandonar sus perspectivas de independencia nacional y sus pretensiones de desarrollo tecnológico propio. 
Estos golpes se basaron en el terror y la tortura, en formas cada vez más duras de acción terrorista de Estado. Se trataba de una nueva modalidad de fascismo. El concepto de fascismo no necesariamente refiere la existencia de partidos o movimientos fascistas; el fascismo se impuso en toda Europa en los años treinta sin contar con partidos fascistas importantes en la mayor parte de los países. Se trataba de un régimen del capital monopólico basado en el terror. Esto fue exactamente lo que se desarrolló entre 1964 y 1976 en América Latina Y otras regiones del Tercer Mundo. Esta modalidad de fascismo inducía a que, en las zonas donde sobrevivía aún alguna condición democrática, se unieran fuerzas para incidir sobre el sistema económico mundial en busca de mejores condiciones de negociación para los países dependientes.

Fue bajo la inspiración de Raúl Prebisch que se constituyó la UNCTAD, a inicios de la décadas de los sesenta, con el fin de articular las reivindicaciones económicas del Tercer Mundo. Fue el gobierno venezolano de Carlos Andrés Pérez el que nacionalizó el petróleo y originó la Organización de Países Exportadores de Petróleo (OPEP), cuya acción de rehabilitación del precio del petróleo sacudió la economía mundial en 1973; y fue el presidente Echeverría de México quién, procurando retomar los principios cardenistas, propone y consigue aprobar en las Naciones Unidas la Carta de los Derechos Económicos de las Naciones y crea el Sistema Económico Latinoamericano (SELA).

Estos cambios expresaban el surgimiento en la arena mundial de los nuevos Estados poscoloniales que significaron un avance del Tercer Mundo. A esto se suma el avance de los países socialistas, en la medida en que muchos de los procesos de transformación del Tercer Mundo se dirigían cada vez más hacia una transición socialista. Estos cambios se manifiestan sobre todo en la creación del Movimiento de los No Alineados, que busca articular políticamente al Tercer Mundo, cobijándose ideológicamente en las tesis lanzadas en 1955 por la Conferencia de Bamdung. Esta conferencia inició un profundo movimiento ideológico, diplomático y político, que representó un intento de repensar el mundo bajo la óptica de aquellos países que habían sido subyugados al régimen colonial durante más de 200 años y que regresaban a la arena internacional como Estados modernos que se apoyaban sobre las grandes civilizaciones de la humanidad. Esta nueva realidad exigía una revisión profunda de la economía mundial. 
Theotônio dos Santos. EI desarrollo latinoamericano: pasado, presente y futuro. Un homenaje a André Gunder Frank

La década de los setenta estuvo marcada por la contraofensiva de la Comisión Trilateral con el objetivo de unir a Estados Unidos, Europa y Japón frente a la ofensiva del Tercer Mundo y del campo socialista. Se apoyó en la política de "Derechos Humanos" del presidente estadounidense James Carter. Se trataba de producir una desvinculación activa de las democracias occidentales con los gobiernos dictatoriales de base militar que ellas habían inspirado poco tiempo atrás. Estos regímenes habían cumplido su papel represivo y empezaban a manifestar pretensiones nacionalistas inaceptables para una economía mundial en globalización.

Esta política de liberalización conservadora continuó en la década de los ochenta bajo la égida de los gobiernos conservadores de Ronald Reagan y Margaret Thatcher, con el apoyo de Helmut Kohl en Alemania y varias experiencias de políticas neoliberales fundadas en el "Consenso de Washington". En este consenso se unían el Fondo Monetario Internacional (FMI), el Banco Mundial y otras agencias internacionales para imponer el "ajuste estructural" a los países dependientes, cercados por una brutal elevación de las tasas de interés internacionales, que convertían sus elevadas deudas externas en fantásticas succionadoras de sus excedentes económicos, llevándolos al estancamiento e incluso al retroceso socioeconómico. Todavía está por ser definitivamente evaluada la profundidad de las transformaciones producidas en la economía mundial durante esta década. Sobre este tema escribí algunos artículos intentando explicar la base de la recuperación económica que tuvo lugar en la economía mundial entre 1983 y 1987, la cual se apoyó en el déficit fiscal estadounidense que lanzó una demanda de centenas de billones de dólares sobre la economía mundial, permitiendo una reactivación de la economía internacional que dejaba para el futuro la cuestión del déficit fiscal estadounidense con todos sus efectos correlativos, a los que estamos asistiendo en la década de los noventa, y entre los cuales se encuentra la crisis que se abatió sobre la economía mundial entre 1989 y 1994.

En este contexto, la teoría de la dependencia fue atacada por la derecha y por la izquierda. Desde la izquierda este ataque venía del sector que sostenía que esta teoría representaba una especie de evolución del pensamiento de la CEPAL, al mantener la importancia de cuestiones como el capital internacional, la economía exportadora y la división internacional del trabajo. De acuerdo con esta posición, se trataba de una teoría que privilegiaba los elementos ligados a la circulación económica sobre los de la 
producción. Según estos críticos, el centro del debate debería estar ubicado en el modo de producción y las relaciones entre las clases sociales, como si éstas no se constituyeran en el interior de los modos de producción y de los sistemas económicos y formaciones sociales concretos.

En verdad esta reacción crítica izquierdista estuvo inspirada en la revolución cultural china y estaba muy influenciada por la idea de una revolución agraria, que sustituía la visión marxista del papel del proletariado moderno. Estas críticas eran una especie de canto de cisne de la visión que atribuía al régimen feudal y a las modalidades de nuestras economías agrarias tradicionales un papel central en las economías latinoamericanas y caribeñas. Irónicamente, fue en la década de los ochenta cuando se terminó con los restos del sistema económico rural orientado al autoconsumo, tanto en América Latina como en África y gran parte de Asia. Las décadas de los setenta y ochenta estuvieron marcadas por la destrucción de las economías de autoconsumo y el lanzamiento de masas gigantescas de las regiones rurales en dirección de las ciudades del Tercer Mundo, generando un fenómeno de marginalidad urbana creciente, concentrada en las grandes metrópolis del Tercer Mundo.

Esta crítica de izquierda no tenía realmente nada que ofrecer, pero hubo también, por otro lado, la reacción conservadora y globalista. Ésta se fundó en la ofensiva Reagan-Thatcher que se constituyó en torno a la recuperación de la economía estadounidense de 1983 a 1989, presentada como generadora de una nueva modalidad de la economía mundial, aunque las formas que asume en la década de los ochenta no son necesariamente las formas finales de una nueva economía mundial globalizada. Por el contrario, en este periodo se producen, desviaciones muy profundas del proceso de globalización, sobre todo la creación de una enorme burbuja financiera internacional. Las transformaciones ocurridas en el campo socialista, con la caída del llamado "imperio soviético" a finales de la década, son presentadas como expresiones de un triunfo total del pensamiento neoliberal en lo económico y lo político. Esta euforia ideológica encuentra su punto más alto en la obra de Fukuyama sobre El fin de la historia. En este libro se dedica un capítulo a la teoría de la dependencia identificándola como el gran enemigo a destruir, como la última modalidad de resistencia al fin de la historia y a la victoria definitiva del capitalismo y del liberalismo en el mundo. 
Theotônio dos Santos. EI desarrollo latinoamericano: pasado, presente y futuro. Un homenaje a André Gunder Frank

Actualmente esta reacción conservadora globalista de la década de los ochenta, que mantenía una cierta adhesión a algunos principios liberales, se encuentra en plena crisis. No solamente por las dificultades económicas para la viabilización de ese modelo que derivan de la recesión, sino también por el desgaste de la ideología neoliberal y su sustitución, en el pensamiento conservador, por tendencias fascistas que están tomando cuerpo en el mundo en la década actual.

Hagamos una recapitulación que nos permita explicar este movimiento histórico. El gobierno de Carter, como vimos, colocó la cuestión de los derechos humanos como objetivo central de su política exterior, confrontándose con los regímenes militares que habían sido creados por Estados Unidos en la década de los sesenta e inicios de la siguiente. Esta confrontación se debía a dos razones fundamentales: primeramente había una razón de carácter más profundo y global que es la contradicción creciente entre el proceso de globalización de la economía mundial y las resistencias de los gobiernos nacionales, apoyados sobre ejércitos nacionales, que terminaban por crear obstáculos al proceso de globalización. El caso extremo fue el de la Revolución peruana que en 1968 estableció un régimen de izquierda comandado por militares. Otro caso considerado extremadamente peligroso era el régimen militar brasileño, donde un radicalismo de derecha, con ligeros tintes nacionalistas y pretensiones de gran potencia, se estableció durante el gobierno de Medici. Este enfoque tuvo también ciertas prolongaciones en el gobierno de Gelsel, con el acuerdo nuclear entre Brasil y Alemania $\mathbf{y}$ otros desplantes de esa modalidad de nacionalismo de derecha. Todo esto conducía a un choque con los intereses del proceso de globalización liderado por las multinacionales por un lado, y con las concepciones geopolíticas del Pentágono, del otro. Otra razón para este enfrentamiento entre el proceso de globalización y los regímenes militares era la necesidad de sustentar la política de derechos humanos como un factor movilizador, como factor de justificación ideológica para el enfrentamiento con los países socialistas y con los regímenes del Tercer Mundo que, en general, no presentaban formas organizativas de tipo liberal democrático.

Al vincular el concepto de derechos humanos con las formas de gobierno liberal se fueron creando condiciones para una ofensiva ideológica contra esos gobiernos que, como vimos, habían sido creados por el capital internacional, que armó y apoyó los golpes de Estado que los originaron. 
La retirada de ese apoyo y la adopción de una política de sustentación de regímenes liberales consiguieron desestabilizar esos regímenes de derecha y abrir camino para reconstruir un sistema liberal democrático en América Latina.

A finales de la década de los setenta aún había condiciones para que esta lucha democrática asumiera un carácter más profundo y no simplemente el de shake up del sistema, sin mayores transformaciones sociales. En la década de los ochenta, progresivamente, el pensamiento conservador va controlando las banderas liberal democráticas. Fue exactamente en este proceso histórico cuando una corriente de la teoría de la dependencia, que tenía en Fernando Henrique Cardoso su expresión más coherente, defendió la tesis de la viabilidad de un proceso de democratización en el interior de un capitalismo dependiente. Esta corriente abandonaba cualquier perspectiva de crítica y de confrontación con el capitalismo dependiente, con sus expresiones monopólicas y sus intereses articulados con el capital internacional. Limitaba sus objetivos reformadores a los objetivos liberales, al proceso de destrucción y de desestabilización de las dictaduras, para construir regímenes democráticos.

Apoyada en la situación internacional esa corriente cobró una gran fuerza y se volvió extremadamente crítica frente a la teoría de la dependencia y sus formulaciones iniciales. Se tornó crítica frente los análisis sobre la creciente dificultad de consolidación de regímenes democráticos en el capitalismo dependiente. Ruy Mauro Marini, Vania Bambirra y yo mantuvimos una posición crítica en relación con el capitalismo monopolista y dependiente pero percibimos, en la década de los setenta, que esos cambios de posición en el sistema capitalista mundial permitirían un avance democrático dentro del capitalismo dependiente. Lo que nos separaba de la otra corriente no era la constatación de esas posibilidades de avance democrático sino la tesis de que éstas sean compatibles con la sobrevivencia de un capitalismo dependiente. Éste es exactamente el punto de divergencia, puesto que mi percepción es la de que la acumulación y el avance democrático de la región desestabilizarán crecientemente al capitalismo dependiente en ella y aumentarán la contradicción entre ese movimiento democrático y la sobrevivencia del capitalismo dependiente.

Otro aspecto importante de la evolución de la teoría de la dependencia y su rumbo, ya en los inicios de los años setenta, para el análisis y la 
Theotônio dos Santos. EI desarrollo latinoamericano: pasado, presente y futuro. Un homenaje a André Gunder Frank

profundización del estudio del sistema económico mundial, se refiere a la toma de posición de Frank (citándonos a Samir Amín y a mí). Este fue el momento de concientización de la necesidad de una teoría del sistema económico mundial. El surgimiento y la maduración de la obra de Immanuel Wallerstein, de comprensión y análisis de la formación histórica de ese sistema mundial bajo una fuerte influencia del pensamiento de Fernand Braudel, tendrá lugar en esos años.

En este periodo André Gunder Frank reforzó su análisis del sistema mundial, extendiéndolo a un periodo histórico muy largo, que se habría formado desde la época del imperio romano, en el año 300 A. C., a través de la ruta de la seda. Las tesis de Frank son muy interesantes pero es necesario discutir las rupturas de continuidad de este proceso. Yo aceptaría la idea de que hay una acumulación histórica en torno a un sistema mundo que va agrupando imperios, reestructurándolos alrededor del Mediterráneo, de África del norte, de India y hasta de China, en torno de la ruta de la seda. No hay duda de que este filón de análisis es sumamente significativo. Nos aparta de la visión puramente latinoamericana, obligando a un análisis de carácter más global. Darcy Ribeiro en el decenio de los setenta y Wolf en los ochenta intentaron un enfoque global de la historia de las civilizaciones que incluía a América Latina, sin embargo no es posible extendernos aquí sobre ellos.

En ambas décadas presenciamos una evolución muy importante de Raúl Prebisch. Al dejar la UNCTAD en 1978 crea la revista de la CEPAL donde escribe un conjunto de ensayos que van a servir de base a su libro sobre el sistema económico centro-periferia, en el cual revisa gran parte de su pensamiento económico, ampliamente influenciado por la teoría de la dependencia. Vamos a encontrar también en la corriente de la CEPAL una inquietud permanente en torno a la necesidad de construir un pensamiento más global sobre el sistema mundo. Esta evolución va a encontrar sus mejores expresiones en los análisis de Fernando Fanzylbert sobre la industrialización trunca, las empresas trasnacionales y la necesidad de un nuevo modelo de desarrollo con equidad Y con una nueva inserción en la economía mundial. Al mismo tiempo Osvaldo Sunkel intenta revivir la teoría del desarrollo en el contexto de un "neoestructuralismo".

En los ochenta América Latina es objeto de una ofensiva liberal muy fuerte a propósito del ajuste de sus economías para pagar la deuda externa. En un 
periodo en que las tasas de interés se elevaron enormemente, la región fue obligada a ajustarse a la creación de un excedente exportador. Se creó un gran superávit comercial para destinarlo al pago de intereses por demás desolladores. Las tesis que nosotros defendimos en esos años -y particularmente André Gunder Frank-, de que la función del capital internacional y del sistema económico mundial era la apropiación y la extracción brutal de excedentes de nuestras regiones, de las regiones dependientes, se mostraron con evidencia. No era ya necesario realizar estudios críticos de las estadísticas de la balanza de pagos, como lo hicieron tan bien Caputo y Pizarro a finales de los años sesenta, porque las propias estadísticas oficiales en el decenio de los ochenta revelaban sin ambages que América Latina era una región exportadora de excedentes y de ahorro.

La generación de este excedente cada vez mayor, que no se convierte en inversión interna porque se destina al pago de intereses y otros tributos coloniales, obligó a un incremento en la distribución negativa de la renta. Para generarlo fue necesaria una rebaja brutal de los niveles salariales y de la participación de los salarios en el ingreso nacional. Por lo tanto, también aumentó la marginación social, la pobreza y, más incluso que la pobreza, la indigencia en el Tercer Mundo y en América Latina. En contraste con esa situación se presentaron durante este periodo los casos relativamente modestos pero exitosos de Corea del Sur, Taiwán, Hong Kong y Singapur, y posteriormente de los llamados tigres menores de Asia. De conformidad con la propaganda oficial éstos son la demostración de la inexistencia de un sistema económico mundial perverso.

Sin embargo, ejemplos propagandísticos como éstos siempre existieron. En la década de los setenta, el llamado "milagro económico brasileño" cumplía el papel de los actuales "tigres asiáticos". En esta década van a tener que ser creados otros modelos puesto que los "tigres asiáticos" se encuentran en una situación económica bastante difícil. En Asia despunta cada vez más el éxito de China Popular bajo el gobierno del Partido Comunista de China. La elección de estos modelos no forma parte de una ciencia económica o social. Se trata de una elaboración ideológica, de una propaganda política para justificar situaciones históricas en las que continúan los graves procesos de explotación entre los pueblos. Buscan desviar el debate de las cuestiones centrales de nuestro tiempo, que no se caracteriza por el equilibrio y convergencia de las diferentes regiones del globo, sino por una creciente brecha entre ricos y pobres, indigentes y marginados. 
El proceso de ajuste estructural en América Latina llevó a un debilitamiento de los Estados latinoamericanos, que transferían sus recursos hacia el sistema económico mundial mientras creaban una gigantesca deuda interna para cuyo pago continúa la transferencia de enormes recursos mediante la imposición de altísimas tasas de interés por el Estado. Estos recursos fueron apropiados por el capital nacional financiero en un primer momento pero, en la etapa actual, con la gran entrada de capitales internacionales de corto plazo, están siendo transferidos en gran medida al capital internacional, que se está incrementando en la región en busca de las elevadas remuneraciones provenientes de los intereses de las deudas públicas, o de las enormes desvalorizaciones de los mercados accionarlos, así como de otras variantes de la especulación.

Los reordenamientos y reestructuraciones permanentes de estas economías para atender las demandas y exigencias del sistema económico mundial continúa siendo la esencia de su historia. Los regímenes dictatoriales fueron impuestos en la región para profundizar la dependencia. Ellos crearon grandes masas marginales y el creciente subaprovechamiento de la mano de obra de la región. Esto ha dificultado la acción política de las fuerzas que se oponen a ese sistema económico. Esto debilita también la capacidad regional para servir al sistema económico mundial. Con el avance de la automatización y de la robotización el desarrollo industrial de la región orientado ahora hacia el mercado mundial, genera cada vez menos empleo. América Latina debe continuar su industrialización pero lo hace aumentando la masa de desempleados y marginados sociales.

Es verdad que todo eso forma un cuadro sumamente desfavorable a una acción política contestataria. También afecta al pensamiento y a la ciencia social, puesto que pierden condiciones de elaboración y medios de investigación, en la medida en que los Estados nacionales también se debilitan seriamente, afectando la capacidad de investigación y desarrollo tanto en el campo de las ciencias naturales y exactas como en el de las ciencias sociales y humanas. Ese cuadro que presenta expectativas más de desolación que de esperanza, podrá, sin embargo, sufrir modificaciones significativas en estos años, en la medida en que el sistema económico mundial tiende a entrar en un proceso de recuperación económica a partir de 1994. 
Un relanzamiento del crecimiento económico podría crear un contexto político internacional más favorable, una rearticulación de las fuerzas interesadas en resolver los grandes problemas de la miseria, del analfabetismo y de las condiciones de vida extremadamente desfavorables para las grandes mayorías poblacionales del mundo. Se trataría de efectuar una apropiación de los adelantos tecnológicos y científicos realizados por la revolución científico-técnica en las últimas décadas para colocarlos al servicio de las poblaciones trabajadoras de todo el mundo.

Son muchos los aspectos en los cuales los países del Tercer Mundo deben desempeñar un papel significativo en la reconstrucción del sistema mundial. Su posición tropical, de receptores de la gran fuente energética solar permite que un desarrollo tecnológico adecuado convierta a esos países en fuentes muy importantes de riqueza, de desarrollo sustentable, en un mundo en que la crisis de la civilización capitalista es también la crisis de un modelo de producción extensiva v de gran desperdicio de energía. Modelo que en este momento se encuentra fuertemente cuestionado por el movimiento verde mundial. De alguna manera, la emergencia de potencias del Tercer Mundo como China, India y Brasil, podrá, junto con otros centros importantes que están localizados en el Tercer Mundo, o fuera de los centros de poder mundial, rectificar gran parte de las tendencias que están en curso en la economía mundial.

Este proceso será, sin embargo, largo y complejo, y exigirá una reforma muy profunda del rumbo actual del desarrollo científico y tecnológico. El avance de la biotecnología, por ejemplo, puede ser extremadamente favorable para una utilización más racional de la biodiversidad que se concentra en las regiones tropicales.

El mundo del siglo XXI rediscutirá la cuestión del desarrollo dentro de principios mucho más amplios y complejos. El desarrollo no estará asociado solamente a la apropiación de la capacidad tecnológica extensiva, generada por la segunda revolución industrial que se extendió de mediados del siglo XIX hasta el decenio de los sesenta, sino también a la apropiación de un conocimiento y una acción económica intensiva, cada vez más cualitativa, promovida por la revolución científico técnica, que es el fundamento de las transformaciones económicas, sociales, políticas y culturales vividas por el mundo después de la segunda guerra mundial. 
Theotônio dos Santos. EI desarrollo latinoamericano: pasado, presente y futuro. Un homenaje a André Gunder Frank

Este cambio de enfoque se liga por lo tanto a un cuestionamiento del orden civilizatorio mundial, del comportamiento y de los fundamentos mismos de la ideología dominante en el mundo liberal capitalista. Los nuevos fundamentos que deberán imponerse serán de contenido mucho más colectivista. Este colectivismo no podrá omitir la gran conquista histórica que representó el nacimiento y crecimiento del individuo como fundamento de la sociedad. Pero no el individuo utilitario pensado por la doctrina liberal y creado por el capitalismo. Se está gestando un nuevo individuo, un individuo que reconoce que su desarrollo es un resultado de la acumulación histórica, económica, social, política y cultural. Un individuo que tendrá que reconocer en su individualidad no una contradicción con lo social sino una realización histórica de lo social. Esa nueva modalidad de civilización establecerá una nueva relación entre el individuo y la sociedad en la cual la sociedad creará o intentará crear individuos con alto potencial de desarrollo y procurará atender sus necesidades para que alcance el máximo de eficiencia social.

Esta nueva sociedad, que deberá emerger durante el siglo XXI, debe ser extensiva a todos los individuos. Este proceso no se confunde con el igualitarismo, que formó parte de los ideales de la civilización liberal burguesa. No se trata de igualitarismo. Se trata de respetar y profundizar la diversidad de los individuos, en una sociedad que dará a cada uno de acuerdo a sus necesidades y demandará de cada uno de acuerdo a su capacidad.

Esa nueva sociedad configurará una nueva civilización planetario. Dentro de ella el asunto del desarrollo tendrá que ser repensado junto con las grandes revisiones del papel del individuo sobre la posición de los hombres y mujeres, en la economía y en la sociedad, sobre la convivencia entre los miembros de etnias diversas, sin aniquilar sus diferencias culturales y físicas y, sobre todo, se tendría que replantear la interacción entre las distintas civilizaciones, que representan experiencias culturales, históricas, económicas y sociales sumamente diferenciadas. Se trata finalmente, de un intento de superación del cuadro económico, social, político y cultural creado por la civilización liberal burguesa, que se confundió históricamente con la hegemonía mundial de Europa y posteriormente de Estados Unidos. Muchas de las características específicas de las sociedades, economías y culturas europeas fueron identificadas con la propia civilización generando el eurocentrismo. Se convirtieron en un instrumento de dominación, de 
subordinación y de expropiación de unas regiones por otras, de ciertos centros y polos de acumulación en detrimento de centros y polos dependientes que producir excedentes brutales para alimentar a esos polos centrales.

Todo este cuadro deberá sufrir una gran transformación, en la cual, durante un largo periodo, las grandes civilizaciones serán referencias sumamente significativas para la construcción de una sociedad plural, de una verdadera civilización planetaria.

\section{NOTA BIBLIOGRÁFICA}

La bibliografía referente al debate sobre la teoría del desarrollo, su versión latinoamericana, y la teoría de la dependencia, su despliegue actual en la teoría del sistema mundo y el nuevo debate sobre el desarrollo de la posguerra fría y pos hegemonía neoliberal y el consenso de Washington no es posible resumirla en las dimensiones de este artículo. Sugerimos al lector interesado en acompañarlo, las siguientes referencias:

- Sobre el debate hasta el año 1977, particularmente en América Latina, véase el capítulo XIX de mi libro Imperialismo y dependencia. México, ERA, 1978.

- Mis reflexiones recientes están en Democracia e Socialismo no Capitalismo Dependente. Petrópolis, Vozes, 1991.

- El libro de Cristóbal Kay (Latin American theories of development and underdevelopemet, Londres, Routledge, 1989) ofrece el mejor resumen de los debates de ese periodo, y su artículo "For a renewal of development studies: Latín American theories and neoliberalism in the era of structural adjustement" ("For a renewal of development studies: Latin American theories and neoliberalism in the era of structural adjustment", Third World Quarterly, vol. 14, núm. 4, 1993) indica con aguda perspicacia algunas rutas actuales del debate. Ambos traen una copiosa bibliografía que recomendamos a los interesados.

- En esta misma línea de rescate del debate teórico del periodo recomendamos: Oman, : C. P. y G. Wignaraja, The postwar evolution of development thinking, Londres, Macmillan, 1991 Blomstróm, Magnus y Bjorn Hettrie, La teoría del desarrollo: en transición, México, Fondo de Cultura Económica, 1990. Y una decena de libros más que están citados en la bibliografía de los trabajos aquí indicados. 
Theotônio dos Santos. EI desarrollo latinoamericano: pasado, presente y futuro. Un homenaje a André Gunder Frank

- André Gunder Frank (El desarrollo del subdesarrollo: un ensayo autobiográfico, Caracas, Nueva Sociedad, 1991) produjo un ensayo autobiográfico en el que analiza buena parte de esta literatura.

- Ronald Chilcote viene acompañando detalladamente este debate desde su Theories of development and underdevelopment, Londres, Westview Press, 1984.

- A.Y. So articula las teorías del desarrollo, de la dependencia y del sistema mundo en su Social change and development: Modernisation, dependency and world system, Newbury Park, Ca, Sage, 1990.

- Ver también Hout, W., Capitalism and Third World: development, dependency and the world system, Edward Elgar, Aldershot, 1993. 